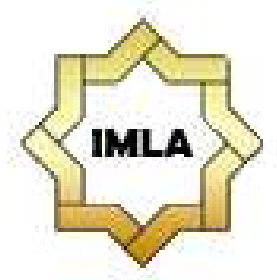

Al-Ta'rib

Jurnal Ilmiah Program Studi Pendidikan Bahasa Arab

IAIN Palangka Raya

Vol. 8, No. 2, December 2020, 147-160

p-ISSN 2354-5887 | e-ISSN 2655-5867

DOI: https://doi.org/10.23971/altarib.v8i2.2282

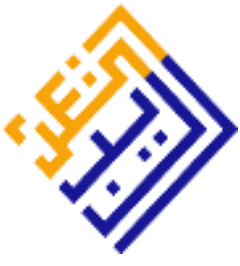

\title{
PEMBELAJARAN MAHARAH AL-ISTIMA' DENGAN MEMANFAATKAN MEDIA YOUTUBE: PROBLEMATIKA DAN SOLUSI
}

\author{
Hamidah', Marsiah' \\ 1,2Institut Agama Islam Negeri Palangka Raya, Indonesia \\ E-mail: hamidah@iain-palangkaraya.ac.id
}

\begin{abstract}
In learning Maharah al-Istima, a lecturer at a college in Palangka Raya uses films from Youtube. Learning to listen to a foreign language cannot separated from problems, but students try to find solutions. This qualitative descriptive study aims to explore the use of films from Youtube in Maharah al-Istima's learning, listening problems and their solutions. The data were collected through observation, interview and documentation techniques, and the data were analyzed through the stages of data collection, data reduction, data presentation and conclusion drawing. The results showed that the lecturer used movies from Youtube offline and online by collecting, selecting, verifying credibility and evaluating the quality of the film. This activity trains students to listen to Arabic and increase their knowledge so that the results of listening of the students are good. The problems faced by students while learning to listen are the fast Arabic pronunciation, the lack of clarity in conversations and the difficulty in vocabulary. Students solve the first problem by playing back, focusing on listening or using dictionaries and other learning strategies. For the second problem, the students overcome them by focusing and understanding the context of the sentences, using a dictionary or other learning strategies. For the third problem, the solution is to train hearing, using a dictionary and reading frequently. The implication of this study is that multimedia communication can help improve the student's listening ability in both offline and online learning.
\end{abstract}

Keywords: Youtube; Maharah al-Istima'; Learning Problem; Solution

\begin{abstract}
Abstrak
Belajar menyimak bahasa asing tidak terlepas dari problematika, namun mahasiswa berupaya mencari solusinya. Penelitian deskriptif kualitatif ini bertujuan untuk mengeksplorasikan pemanfaatan film dari Youtube pada pembelajaran Maharah alIstima, problematika menyimak dan solusinya. Data digali melalui teknik observasi, wawancara dan dokumentasi, dan dianalisis melalui tahap pengumpulan data, reduksi data, penyajian data dan penarikan kesimpulan. Hasil penelitian menunjukkan bahwa dosen memanfaatkan film dari Youtube secara Offline dan online dengan cara mengumpulkan, memilih, memverifikasi kredibilitas dan
\end{abstract}


mengevaluasi kualitas film. Kegiatan ini melatih mahasiswa menyimak bahasa Arab dan menambah pengetahuan sehingga hasil menyimak mahasiswa bagus. Problematika yang dihadapi mahasiswa selama belajar menyimak yakni cepatnya pengucapan orang Arab, kurang jelasnya percakapan dan terdapat kosa kata sulit. Mahasiswa mengatasi problematika yang pertama dengan memutar ulang, fokus mendengarkan atau menggunakan kamus dan strategi belajar lainnya. Untuk problematika yang kedua mahasiswa mengatasinya dengan fokus dan memahami konteks kalimat, menggunakan kamus atau strategi belajar lainnya. Untuk problematika ketiga solusinya adalah melatih pendengaran, menggunakan kamus dan sering membaca. Implikasi dari penelitian ini adalah bahwa multimedia communication dapat membantu meningkatkan kemampuan menyimak bahasa asing si pelajar baik pada pembelajaran offline maupun online.

Kata Kunci: Pemanfaatan Youtube; Maharah al-Istima'; Problematika Belajar; Solusi

\section{Pendahuluan}

Orientasi mempelajari bahasa Arab kini semakin bertambah dari orientasi relegius hingga profesionalisme dan ekonomis. Dari itu, setiap muslim wajib mempelajari bahasa Arab setidaknya untuk membantu dirinya dalam menjalankan ibadah shalat yang ucapan dalam pelaksanaannya menggunakan bahasa Arab yang semestinya dipahami, setidaknya pula minimal memahami teks berbahasa Arab bagi yang memperdalam ilmu agama, dan lebih dari itu harus meningkatkan keterampilan berbahasa Arab yakni maharah al-istima, maharah al-kalam, maharah al-qiraah dan maharah al-kitabah bagi guru bahasa Arab dan akademisi (Hamidah, 2019), termasuk mahasiswa Program Studi Pendidikan Bahasa Arab sebagai calon guru Mata Pelajaran Bahasa Arab atau yang berkecimpung di bidang pendidikan bahasa Arab.

Keterampilan berbahasa yang harus terlebih dahulu dikuasai oleh pelajar adalah menyimak, karena secara alamiah pertama kali manusia memahami bahasa orang lain lewat pendengaran (Hermawan, 2011). Menyimak merupakan kegiatan yang sangat penting. Hasil penelitian menunjukkan bahwa pelajar yang menyimak dengan lebih baik adalah pelajar yang lebih baik. Pendengar yang efektif akan mencapai keberhasilan akademis (Adams, 1946). Jadi belajar keterampilan menyimak memang sangat penting dan harus diperhatikan untuk mendukung tercapainya keberhasilan belajar yang lainnya.

Keterampilan menyimak (maharah al-istima) adalah kemampuan seseorang dalam mencerna dan memahami kata atau kalimat yang diujarkan oleh mitra bicara atau media tertentu (Nuha, 2016). Pembelajaran menyimak ada dua macam. Pertama menyimak untuk keperluan pengulangan agar siswa terbiasa dengan keadaan atau dalam situasi berbahasa. Kedua menyimak untuk memahami teks agar siswa dapat memahami sebuah teks dengan baik, dapat membedakan ide pokok dan tambahan, memahami alur ceritera, dan lain sebagainya (Zainuddin \& Radliyah, 2005).

Dalam pembelajaran menyimak, digunakan teks yang diperdengarkan baik secara langsung maupun dengan menggunakan media pembelajaran. Media 
pembelajaran digunakan dalam penerapan teknologi pendidikan, agar dalam menyampaikan pesan dalam bentuk materi mudah diterima dengan baik oleh si pelajar. Konsep dasar teknologi pendidikan adalah untuk memajukan pengetahuan yang di dalamnya termasuk memediasi dan meningkatkan belajar dan kinerja melalui berbagai langkah strategis dari proses desain, manajemen, dan pelaksanaan belajar dan pembelajaran, dan salah satu kawasan teknologi pendidikan adalah penggunaan ("TPEN4311 - Teknologi Pendidikan Dalam Pendidikan Jarak Jauh," 2019). Teknologi informasi dan komunikasi juga digunakan sebagai media pembelajaran, baik bersifat offline maupun online. Dengan kemampuan teknologi yang dimiliki, komputer menjadi sarana yang sangat efektif dan efisien untuk digunakan sebagai modalitas dalam pembelajaran. Teknologi komputer menjadi banyak ragam dalam pembelajaran ketika terkoneksi dengan internet (Prawiradilaga, 2016).

Biasanya dalam pembelajaran menyimak digunakan media audio seperti seperangkat alat audio yang terdapat di laboraturium bahasa, namun tidak menutup kemungkinan pengajar memanfaatkan media audio visual seperti film. Menurut Marchant film merupakan sarana intelektual dalam berkomunikasi secara emosional dengan siswa sehingga dapat mengatur perilaku rasional siswa (Marchant, 1972), dan sangat baik digunakan di kelas bahasa, terutama di kelas bahasa asing (Julaikah, 2017). Film juga bisa diakses di aplikasi Youtube. Mencari video tentang ilmu pengetahuan di Youtube merupakan sebuah pilihan bebas dalam mempelajari ilmu pengetahuan (Rosenthal, 2018). Youtube juga menjadi salah satu materi multi media interaktif yang digunakan dosen dalam mengajar bahasa Arab khususnya Nahwu dan Sharaf. Dengan menggunakan multimedia interaktif, dosen menjadi lebih mudah dalam mendemonstrasikan bahan ajar atau materi pembelajaran kepada mahasiswa dan dapat menarik minat dan perhatian mahasiswa yang kurang mempunyai motivasi dalam belajar bahasa Arab (Ilmiani et al., 2020).

Membuka Youtube bisa melalui handphone android yang mudah dibawa ke mana saja dan dapat dimanfaatkan untuk pendidikan (Mubarak et al., 2020), termasuk juga pembelajaran menyimak bahasa Arab, dan dari hasil penelitian ditemukan bahwa dengan memanfaatkan ponsel android pembelajaran menyimak menjadi lebih efektif (Jubaidah et al., 2020), juga ada perbedaan yang signifikan antara prestasi dan minat siswa terhadap sejarah dengan menggunakan Youtube Audio-visual documentaries dengan mereka yang tidak diajar (Azor et al., 2020).

Media pembelajaran memang sangat bermanfaat, dan berpengaruh positif terhadap motivasi belajar dan hasil belajar siswa (Marintan, 2017), khususnya belajar bahasa Arab (Putri, 2017). Media dan sumber belajar bahasa Arab berbasis TIK yang memperbanyak tayangan dari penutur asli memiliki pengaruh lebih baik terhadap peningkatan motivasi, kepercayaan diri, dan kompetensi berbahasa Arab para peserta didik (Makruf, 2020).

Memanfaatkan media film di aplikasi Youtube juga dilakukan dosen pada sebuah perguruan tinggi di Palangka Raya dalam mengajar Maharah al-Istima. Dalam pembelajaran Maharah al-Istima, dosen menggunakan film pada Youtube, karena semua mahasiswa memiliki handphone android, sehingga bisa dimanfaatkan untuk belajar dan latihan di rumah. Semakin meningkat level maharah istima semakin meningkat pula kesulitan teks, jadi untuk menambah 
sumber bisa dimanfaatkan berbagai film berbahasa Arab fusha dengan tingkatan durasi yang berbeda. Dalam pembelajaran yang menggunakan film durasi dan kecepatan berbicara dari native speaker dan lainnya, terdapat kesulitan yang dihadapi mahasiswa, namun mahasiswa selalu berupaya mengatasi kesulitan tersebut, guna mencapai tujuan yang diharapkan.

Belajar menyimak bahasa asing memang tidak terlepas dari problematika, karena setiap bahasa memiliki karakteristik masing-masing. Problematika pembelajaran bahasa Arab terdiri dari faktor linguistik mencakup problem tata bunyi, kosa kata, tata kalimat dan tulisan, dan faktor non linguistik yang mencakup factor sosio kultural dan sosial budaya (Nuha, 2016). Beberapa penelitian menemukan bahwa problematika belajar bahasa Arab yang dihadapi mahasiswa di antaranya seperti suara native, keterbatasan vocabulary, cepatnya pembicaraan native, kurang konsentrasi belajar, kelelahan, malas, tidak senang dengan bahasa Arab karena menganggap sulit, sulitnya memilih kata, kesulitan pada semua keterampilan berbahasa termasuk mengaplikasikan nahwu dan sharaf, pelafalan dan pemaknaan kata atau kalimat (Mochammad \& Syairozi, 2017; Ms et al., 2012; Muradi \& Hasbullah, 2016; Nuraeny, 2016).

Penelitian tentang pemanfaatan teknologi pendidikan, problematika belajar bahasa Arab dan solusinya memang banyak telah dilakukan, namun masih jarang ditemukan pemanfaatan film dari Youtube untuk pembelajaran istima, problematika menyimaknya dengan jenjang dan macam kesulitannya serta solusi mengatasinya. Penelitian ini bertujuan untuk mengeksplorasikan pemanfaatan film dari Youtube pada pembelajaran Maharah al-Istima, problematika menyimak film berbahasa Arab bagi mahasiswa dan solusinya.

\section{Metode}

Penelitian kualitatif deskriptif ini dilaksanakan di sebuah perguruan tinggi di Palangka Raya dengan meneliti 13 mahasiswa yang sedang mengikuti Mata Kuliah Maharah al-Istima' sebagai subjek penelitian. Kegiatan menyimak film di Youtube yang dilakukan mahasiswa adalah melalui pembelajaran di kelas dan juga di rumah sebagai tugas dari dosen, sehingga penggalian data dilakukan melalui teknik observasi, wawancara dan dokumentasi.

Teknik wawancara dilakukan untuk menggali data tentang problematika belajar menyimak film berbahasa Arab dati Youtube dan solusinya. Data tersebut juga digali melalui observasi saat pembelajaran di kelas dengan nonton bareng di smart TV. Teknik dokumentasi juga digunakan untuk menguatkan data yang diperoleh dari kedua teknik tadi dengan melihat hasil pemahaman tertulis mahasiswa setelah menyimak isi film tersebut.

Analisis data dilakukan pada saat pengumpulan data berlangsung, dan setelah selesai pengumpulan data dalam periode tertentu. Langkah-langkah analisis data dilakukan dengan pengumpulan data, reduksi data, penyajian data dan penarikan kesimpulan. Selanjutnya dilakukan pemeriksaan keabsahan data dengan menggunakan trianggulasi data yang memanfaatkan sesuatu yang lain di luar data itu untuk keperluan pengecekan atau sebagai pembanding terhadap data tersebut. 


\section{Hasil dan Pembahasan \\ Pemanfaatan Film dari Youtube pada Pembelajaran Maharah al-Istima}

Mata kuliah Maharah al-Istima' diajarkan dengan tujuan agar mahasiswa mampu memahami wacana berbahasa Arab yang dituturkan oleh penutur asli secara langsung atau melalui media dan mampu menganalisisnya. Untuk mempermudah mahasiswa menguasai kompetensi tersebut, dalam perkuliahan dosen memanfaatkan media film dari Youtube yang mana dengan mudah mahasiswa mendapatkannya, karena semua mahasiswa memiliki smart phone. Hasil atau pemahaman menyimak dalam mahasiswa film dari Youtube pada umumnya bagus.

Berdasarkan temuan Jones a \& Kristen Cuthrell (2011) bahwa Youtube dapat dimanfaatkan tenaga pendidik dalam pembelajaran dengan berbagai cara, dengan tetap memverifikasi kredibilitas video dan mengevaluasi kualitasnya, maka dosen memanfaatkan Youtube pada pembelajaran Maharah al-Istima dengan cara menggunakannya saat pembelajaran di kelas dengan cara nonton bareng di smart TV dan pemberian tugas melalui beberapa aplikasi untuk latihan menyimak di rumah mengingat kegiatan belajar menyimak memerlukan banyak waktu (Jones \& Cuthrell, 2011).

Langkah pertama yang dilakukan dosen adalah menganalisis kompetensi yang akan dimiliki mahasiswa setelah mengikuti mata kuliah Maharah al-Istima. Langkah kedua mengumpulkan bahan berupa film di Youtube yang sesuai dengan tujuan perkuliahan. Setelah dikumpulkan dan dipilih, film diverifikasi kredibilitasnya dengan membandingkan pesan film dari Youtube dengan beberapa sumber lainnya yang dapat dipercaya. Langkah ketiga mengevaluasi kualitasnya menganalisis kelayakan bahan tersebut dari segi penyajian dan teknis seperti kejelasan suara dan gambar.

Pembelajaran menyimak yang dilaksanakan oleh dosen dengan memanfaatkan film dari Youtube ini sesuai dengan hasil penelitian Moghavvemy, Ainin Sulaiman, Noor Ismawati Jaafar, Nafisa Kasem, (2018) bahwa pembelajaran menjadi lebih efektif ketika siswa mencari informasi akademik dan belajar melalui Youtube dengan intens, dan hal ini mengharuskan guru menerapkan teknologi yang sesuai (Moghavvemi et al., 2018).

Menurut mahasiswa, menggunakan film dari Youtube dalam pembelajaran Maharah al-Istima sangat bermanfaat, karena dapat melatih mereka dalam skill pendengaran, logat orang Arab asli dan terbiasa mendengar perkataan-perkataan orang Arab dan menambah pengetahuan. Manfaat penggunaan film dalam pembelajaran ini sama juga dengan yang dirasakan oleh guru dan siswa atau mahasiswa yang diketahui dari hasil penelitian yakni film dapat membantu belajar (Stebleton et al., 2011). Belajar dengan memanfaatkan Youtube dapat meningkatkan minat dan efisiensi, memperkaya konten (Tamim, 2013), meningkatkan pemahaman tentang konsep yang diajarkan di kelas dengan informasi yang sangat akurat dan disajikan dalam format yang bermanfaat (Tella et al., 2020). Belajar bahasa asing di Youtube dianggap lebih fleksibel, lebih menarik, dan lebih interaktif daripada pembelajaran formal di kelas (Wang \& Chen, 2020). 


\section{Problematika Menyimak Film Berbahasa Arab dari Youtube}

Dalam menyimak film berbahasa Arab yang diperankan oleh orang Arab asli ataupun kartun dari Youtube, di mana pembicaraan atau percakapan agak cepat, maka mahasiswa merasa kesulitan jika hanya sekali menyimaknya, dan terkadang mahasiswa sulit memahaminya. Percakapan tersebut tidak bisa dihindari karena memang pada kenyataannya atau aslinya orang bertutur memang seperti itu. Oleh karena itu digali data tentang problematika apa saja yang dihadapi mahasiswa dalam menyimak film berbahasa Arab dan bagaimana mereka mengatasinya, untuk kemudian bisa diterapkan pada masa-masa berikutnya dan berbagi ilmu dengan mahasiswa atau pelajar lainnya yang ingin mendalami bahasa Arab, serta dosen dan pengajar lainnya bisa menambahkan solusinya agar kompetensi yang diharapkan dapat dikuasai.

Adapun problematika yang dihadapi mahasiswa dalam menyimak film berbahasa Arab pada mata kuliah Maharah al-Istima sebagaimana tabel berikut:

TABEL 1

Problematika Menyimak Film Berbahasa Arab dari Youtube

\begin{tabular}{llll}
\hline No. & \multicolumn{1}{c}{ Problematika } & \multicolumn{1}{c}{ Subjek Penelitian } & Jumlah \\
\hline 1 & $\begin{array}{l}\text { Cepatnya pengucapan atau } \\
\text { percakapan }\end{array}$ & MDN, IS, ASN, SA, TN, ThN, AW, & 13 \\
2 & $\begin{array}{l}\text { Kosa kata asing yang belum } \\
\text { tahu artinya }\end{array}$ & IS, FAM, NA, MNAP, SA & 5 \\
3 & Percakapan kurang jelas & MOR, MNAP & 2 \\
\hline
\end{tabular}

Terdapat tiga problematika menyimak film berbahasa Arab dari 13 mahasiswa yakni cepatnya pengucapan orang Arab, percakapan kadang kurang jelas dan terdapat kosa kata yang sulit. Semua mahasiswa merasa kesulitan memahami pembicaraan orang Arab yang cepat. Cepatnya pembicaraan berbahasa Arab dalam film, karena memang bahasa Arab itu adalah bahasa mereka. Bagi orang yang menguasai bangsa tertentu wajar cepat berbicara. Apalagi film yang dibuat bertujuan untuk memberikan pesan, informasi dan hiburan, bukan bertujuan khusus untuk pembelajaran khusus, hanya saja dosen memanfaatkannya untuk pembelajaran, sehingga terdapat kendala dan perlu penyesuaian. Wajar setiap orang yang memperlajari bahasa asing akan kesulitan karena pertama memang bukan bahasa yang mereka pergunakan dalam percakapan sehari-hari, kedua tidak terbiasa menggunakan bahasa tersebut.

Kosa kata yang sulit juga menjadi salah satu problematika yang sering dihadapi mahasiswa, karena setiap bangsa memiliki bahasa masing-masing, yang kalau dipelajari orang asing akan menemukan kosa kata yang belum diketahui artinya, namun mahasiswa yang mengalami kesulitan memahami film berbahasa Arab karena faktor ini hanya 5 orang saja dari 13 orang. Setiap bahasa memiliki karakteristik masing-masing sebagaimana yang dikatakan Rosyidi (2011) bahwa bahasa Arab memiliki karakteristik sendiri yang merupakan kelebihan yang tidak ada pada bahasa lain (Rosyidi \& Ni'mah, 2011). 
Kosa kata yang belum tahu artinya yang disebut juga kosa kata yang sulit menjadi salah satu problematika yang sering dihadapi mahasiswa. Hal ini wajar mengingat bahasa Arab bukanlah bahasa yang mereka gunakan sehari-hari, meskipun mereka setiap harinya belajar bahasa Arab, namun tertulis dan lisan juga bisa mempengaruhi daya tangkap menyimak kosa kata karena harus membayangkan tulisannya.

Percakapan kurang jelas merupakan salah satu problematika menyimak film berbahasa Arab. Hal ini disebabkan karena cepatnya percakapan dan juga kendala tehnis seperti suara dari film yang kurang jelas dan sebagainya, namun yang mengalami kendala dalam memahami film berbahasa Arab karena faktor ini hanya sebagian kecil saja yakni 2 orang dari 13 orang mahasiswa. Sebuah media kemungkinan akan mengalami hal sesuai kualitas pembuatan beberapa permasalahan yang dihadapi mahasiswa dalam penggunaan yutube adalah hal yang wajar, sebagaimana yang disebutkan Tamim bahwa konektivitas, masalah teknis, kesesuaian kesatuan konten, dan dukungan administratif dianggap sebagai tantangan utama pada penggunaan Youtube dalam pembelajaran (Tamim, 2013).

\section{Solusi dalam Mengatasi Problematika Menyimak Film Berbahasa Arab dari Youtube}

Dari berbagai problematika yang dihadapi mahasiswa dalam belajar menyimak film berbahasa Arab, mahasiswa berupaya mencari solusi guna memahami percakapan bahasa Arab tersebut. Berikut solusi yang mereka upayakan:

TABEL 2

Solusi Problematika Menyimak Film Berbahasa Arab dari Youtube

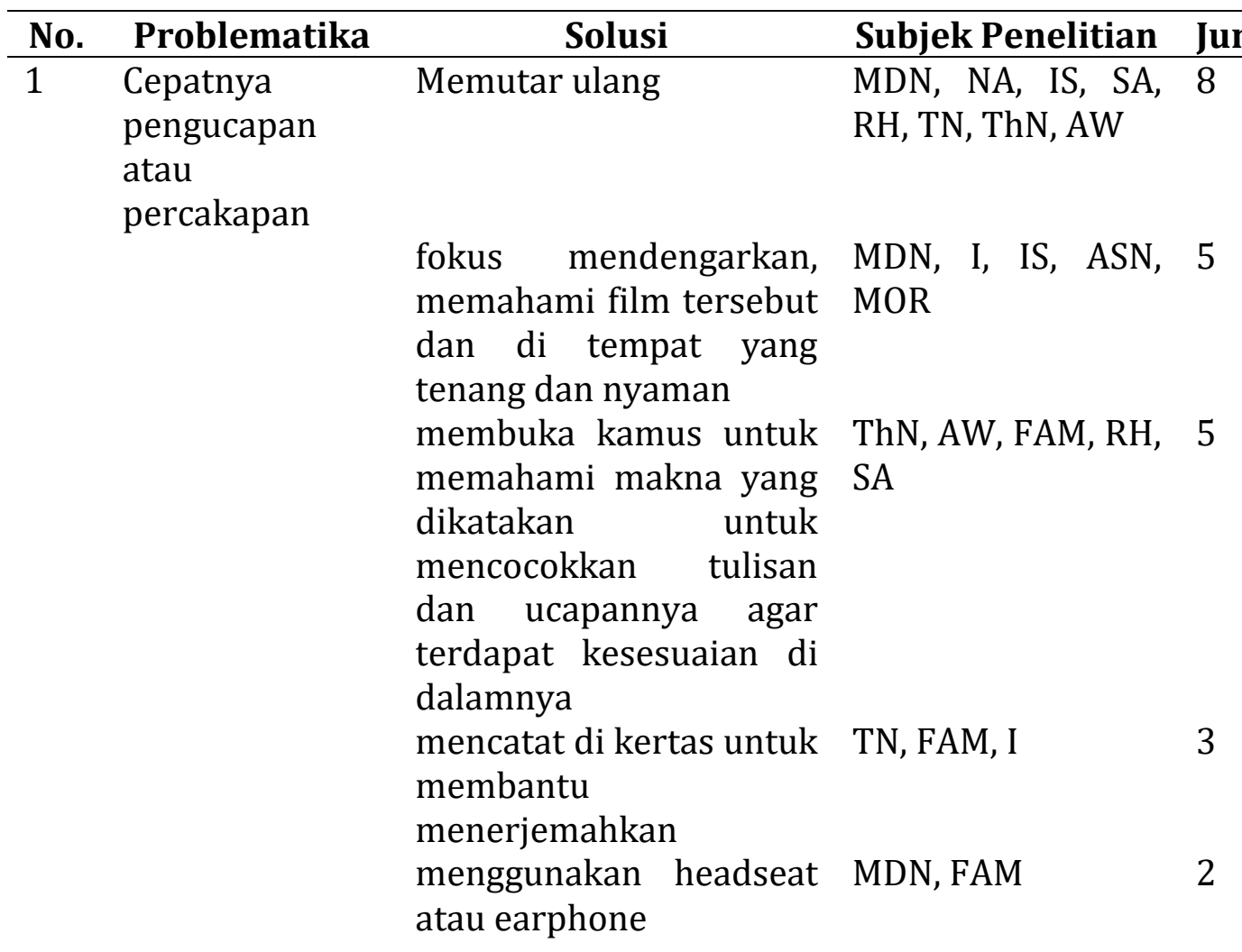




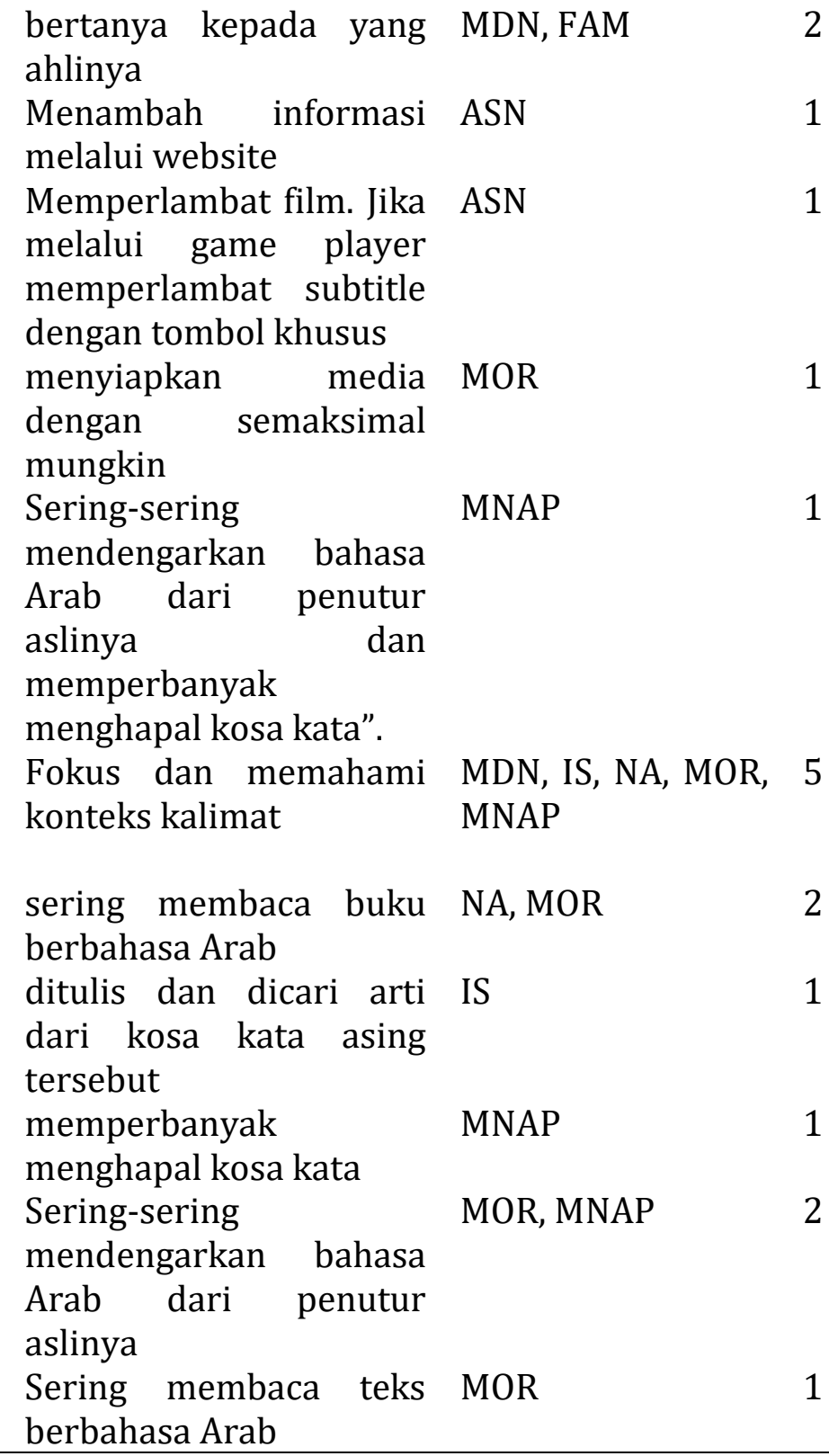

Ada tiga macam solusi yang dilakukan oleh 13 mahasiswa dalam mengatasi problematika cepatnya pengucapan atau percakapan dalam menyimak film berbahasa Arab di Youtube yakni dengan memutar ulang, fokus mendengarkan di tempat yang tenang dan nyaman atau menggunakan kamus. Ada sebagian kecil mahasiswa menambahkan solusinya selain yang tiga macam tersebut yakni dengan mencatat dan menerjemahkan, menggunakan hadseat agar lebih fokus, bertanya kepada yang lebih megetahui, memperlambat film, menambah informasi di website dan sering mendengarkan pembicaraan native dalam bahasa Arab.

Untuk problematika kosa kata asing yang belum tahu artinya dalam menyimak film kebanyakan mahasiswa mengatasinya dengan fokus dan memahami konteks kalimat atau menggunakan kamus untuk mengetahui artinya. Ada di antara mahasiswa menambahkan solusinya dengan sering membaca buku 
berbahahsa Arab, mencari artinya dengan menulis terlebih dahulu dan memperbanyak kosa kata dengan menghapal. Untuk problematika kurang jelasnya percakapan dalam menyimak film, solusi yang dilakukan mahasiswa adalah melatih pendengaran suara terbiasa dengan bahasa asing, menggunakan kamus dan ada yang menambahkan dengan sering-sering membaca teks berbahasa Arab.

Fokus terhadap apa yang didengar adalah konsentrasi dengan apa yang sedang dipelajari. Konsentrasi merupakan pemusatan perhatian dalam proses dalam menyimak film berbahasa Arab. Jika konsentrasi rendah, maka akan menimbulkan aktivitas yang berkualitas rendah pula serta dapat menimbulkan ketidakseriusan dalam belajar dan daya pemahaman terhadap materi pun menjadi berkurang. Konsentrasi merupakan modal utama bagi siswa dalam menerima materi ajar serta menjadi indikator suksesnya pelaksanaan pembelajaran (Aviana \& Hidayah, 2015).

Menggunakan kamus juga merupakan solusi yang banyak dilakukan mahasiswa dalam mengatasi problematika cepatnya pengucapan atau percakapan dalam menyimak film berbahasa Arab di Youtube, karena kamus merupakan rujukan untuk mengetahui makna kata-kata, terutama kata-kata yang belum diketahui artinya dan juga contoh penggunaannya dalam kalimat, sehingga pengguna kamus dapat memahami arti kata yang tepat dalam kalimat.

Banyak solusi yang mahasiswa lakukan terhadap berbagai problematika dalam memahami film berbahasa Arab seperti mengulang, mencatat, menghapal, menerjemahkan, memahami konteks kalimat, fokus pada apa yang disimak dan strategi metakognitif seperti menggunakan alat bantu, memperlambat film, bertanya kepada ahlinya, belajar di tempat yang tenang. membiasakan mendengar dan membaca teks berbahasa Arab. Semua yang dilakukan mahasiswa tersebut merupakan upaya agar dapat menguasai kompetensi yang diinginkan yakni memahami film berbahasa Arab yang diperdengarkan dan mampu menganalisisnya.

Apa yang mahasiswa upayakan dalam mengatasi problematika belajar menyimak tersebut sama dengan yang disebutkan Al-Tabany (2014) bahwa berdasarkan teori kognitif dan teori pemrosesan informasi, terdapat beberapa strategi belajar yang dapat digunakan yaitu strategi mengulang, strategi elaborasi, strategi organisasi dan strategi metakognitif, dan juga yang disebutkan Syah dalam Priansa (2017) bahwa faktor yang mempengaruhi belajar terdiri atas faktor internal, faktor eksternal dan faktor pendekatan belajar (Al-Tabany, 2015; Priansa;, 2017).

Beberapa hasil penelitian juga ditemukan solusi yang dilakukan dalam mengatasi problematika belajar bahasa Arab mahasiswa sebagaimana yang mahasiswa upayakan tadi seperti mengevaluasi cara belajar, menggunakan strategi memori, afektif, kognitif dan metakognitif dalam belajar (Marintan, 2017; Muradi \& Hasbullah, 2016), seperti latihan membuat kalimat, membuat catatan dan menerjemahkan (Mochammad \& Syairozi, 2017), mengidentifikasi makna kata sulit dengan menggunakan kamus, bertanya kepada teman dan memanfaatkan konteks (Asrori, 2016). Mahasiswa juga bisa belajar mandiri dengan memanfaatkan sarana yang tersedia untuk menambah informasi dan pengetahuan (Ma'shomah, 2017), dan memanfaatkan teknologi informasi (Haniah, 2014). 


\section{Kesimpulan}

Pemanfaatkan film dari Youtube pada pembelajaran Maharah al-Istima' secara offline atau online dilakukan dengan terlebih dahulu mengumpulkan, memilih, memverifikasi kredibilitasnya dan mengevaluasi kualitasnya. Kegiatan ini melatih mahasiswa dalam mendengar perkataan orang Arab, menambah pengetahuan dan hasil menyimak merekapun juga bagus. Problematika menyimak yang dirasakan mahasiswa yakni cepatnya pengucapan orang Arab, percakapan kurang jelas dan terdapat kosa kata yang sulit. Solusi yang dilakukan mahasiswa dalam mengatasi problematika pertama adalah dengan memutar ulang, fokus mendengarkan di tempat yang tenang atau menggunakan kamus, selain itu juga ada yang mencatat dan menerjemahkan, menggunakan hadseat, bertanya kepada yang lebih megetahui, memperlambat film, menambah informasi di website dan sering mendengarkan pembicaraan native dalam bahasa Arab. Untuk problematika kedua mahasiswa mengatasinya dengan fokus dan memahami konteks kalimat atau menggunakan kamus untuk mengetahui artinya, di antara meraka ada yang menambahkan solusinya dengan sering membaca buku berbahasa Arab, mencari artinya dengan menulis terlebih dahulu dan memperbanyak kosa kata dengan menghapal. Untuk problematika ketiga, solusi yang dilakukan mahasiswa adalah melatih pendengaran terbiasa dengan bahasa asing, menggunakan kamus dan ada yang menambahkan dengan sering-sering membaca teks berbahasa Arab. Implikasi dari penelitian ini adalah bahwa multimedia communication dapat membantu meningkatkan kemampuan menyimak bahasa asing si pelajar baik secara offline maupun online.

\section{Referensi}

Adams, H. M. (1946). Learning to Listen. The Clearing House: A Journal of Educational Strategies, Issues and Ideas, 20(7), 401-403. https://doi.org/10.1080/00098655.1946.11473767

Al-Tabany, T. I. B. (2015). Mendesain Model Pembelajaran Inovatif, Progresif, dan Kontekstual: Konsep Landasan dan Implementasinya pada Kurikulum 2013 (Jakarta). Prenadamedia Group. //fia.ub.ac.id/katalog/index.php?p=show_detail\&id=949\&keywords=

Asrori, I. (2016). Strategi Pembelajar Indonesia Mengidentifikasi Makna Kata Bahasa Arab dalam Konteks Kalimat Wacana Geografi. Arabi: Journal of Arabic Studies, 1(2), 11-23. https://doi.org/10.24865/ajas.v1i2.4

Aviana, R., \& Hidayah, F. F. (2015). Pengaruh Tingkat Konsentrasi Belajar Siswa terhadap Daya Pemahaman Materi pada Pembelajaran Kimia di SMA Negeri 2 Batang. JURNAL PENDIDIKAN SAINS (JPS), 3(1), 30-33. https://doi.org/10.26714/jps.3.1.2015.30-33

Azor, R. O., Asogwa, U. D., Ogwu, E. N., \& Apeh, A. A. (2020). YouTube audio-visual documentaries: Effect on Nigeria students' achievement and interest in history curriculum. The Journal of Educational Research, 113(5), 317-326. https://doi.org/10.1080/00220671.2020.1819182 
Hamidah, H. (2019). Arabic Language: Between Learning Necessity and Responsibility (ar). Al-Ta'rib: Jurnal Ilmiah Program Studi Pendidikan Bahasa Arab IAIN Palangka Raya, 7(1), 35-44. https://doi.org/10.23971/altarib.v7i1.1472

Haniah, H. (2014). Pemanfaatan Teknologi Informasi dalam Mengatasi Masalah Belajar Bahasa Arab. Al-Ta'rib: Jurnal Ilmiah Program Studi Pendidikan Bahasa Arab PalN Rangka Ra, 2(1). https://doi.org/10.23971/altarib.v2i1.588

Hermawan, A. (2011). Metodologi Pembelajaran Bahasa Arab. Remaja Rosdakarya.

Ilmiani, A. M., Ahmadi, A., Rahman, N. F., \& Rahmah, Y. (2020). Multimedia Interaktif untuk Mengatasi Problematika Pembelajaran Bahasa Arab. AlTa'rib : Jurnal Ilmiah Program Studi Pendidikan Bahasa Arab IAIN Palangka Raya, 8(1), 17-32. https://doi.org/10.23971/altarib.v8i1.1902

Jones, T., \& Cuthrell, K. (2011). YouTube: Educational Potentials and Pitfalls. Computers in the Schools, 28(1), 75-85. https://doi.org/10.1080/07380569.2011.553149

Jubaidah, S., Pimada, L. H., Yurisa, P. R., \& Wargadinata, W. (2020). Fa'āliyyah Ta'līm Mahārah al-Istimā' bi Istikhdām Android li al-Jawwāl. LISANIA: Journal of Arabic Education and Literature, 4(1), 49-64. https://doi.org/10.18326/lisania.v4i1.49-64

Julaikah, D. I. (2017). Menghadirkan Film dalam Pembelajaran Bahasa Jerman Sebagai Bahasa Asing (DEUTSCH ALS FREMDSPRACHE). Paramasastra, 4(1), Article 1. https://doi.org/10.26740/parama.v4n1.p\%p

Makruf, I. (2020). Pemanfaatan Teknologi Informasi dan Komunikasi dalam Pembelajaran Bahasa Arab di Madrasan Aliyah Kabupaten Sukoharjo. Arabi : Journal of Arabic Studies, 5(1), 79-90. https://doi.org/10.24865/ajas.v5i1.93

Marchant, G. C. (1972). The Efficiency of Film in Education. Educational Media International, 1, 11-12.

Marintan, D. (2017). Pengaruh Media Pembelajaran dan Strategi Belajar Terhadap Hasil Belajar Siswa Kelas X Pada Mata Pelajaran Ekonomi SMA Sedes Sapientiae Semarang, (studi pada tahun ajaran 2015/2016),. Economic Education Analysis Journal, 6(1), 12.

Ma'shomah, M. (2017). Istiratijiyyat al-Ta'allum al-Dzati li Thalabah al-Marhalah al-Jami'ah. Al-Ta'rib: Jurnal Ilmiah Program Studi Pendidikan Bahasa Arab IAIN Palangka Raya, 5(1), 1-13. https://doi.org/10.23971/altarib.v5i1.764

Mochammad, P. B., \& Syairozi, W. M. (2017). Istiratijiyat Talamidz Al-Marhalah AlTsanawiyah bi Ma'had Darussalam Gontor fi Ta'allum Maharah Al-Kitabah. Arabiyat: Jurnal Pendidikan Bahasa Arab dan Kebahasaaraban, 4(1), 102111. https://doi.org/10.15408/a.v4i1.5329 
Moghavvemi, S., Sulaiman, A., Jaafar, N. I., \& Kasem, N. (2018). Social Media as a Complementary Learning Tool for Teaching and Learning: The Case of Youtube (SSRN Scholarly Paper ID 3140146). Social Science Research Network. https://papers.ssrn.com/abstract=3140146

Ms, S. S. U., Ariwidodo, E., \& Rabiyanti, E. N. (2012). Problematika dalam Belajar Listening Comprehension yang dihadapi Oleh Mahasiswa Semester III Tadris Bahasa Inggris STAIN Pamengkasan. NUANSA: Jurnal Penelitian Ilmu Sosial dan Keagamaan Islam, 9(1), Article 1. https://doi.org/10.19105/nuansa.v9i1.23

Mubarak, M. R., Wahdah, N., Ilmiani, A. M., \& Hamidah, H. (2020). Penggunaan Vlog Dalam Pembelajaran Mahārah Kalām. Al Mi'yar: Jurnal Ilmiah Pembelajaran Bahasa Arab dan Kebahasaaraban, 3(1), 109-126. https://doi.org/10.35931/am.v3i1.209

Muradi, A., \& Hasbullah, H. (2016). Strategi Belajar Bahasa Arab Mahasiswa Prodi PBA IAIN Antasari Banjarmasin Menurut Model Oxpord. LiNGUA: Jurnal Ilmu Bahasa Dan Sastra, 11(1), 54-62. https://doi.org/10.18860/ling.v11i1.3413

Nuha, U. (2016). Ragam Metodologi \& Media Pembelajaran Bahasa Arab. Diva Press.

Nuraeny, Y. (2016). Strategi Mengatasi Kesulitan Belajar Bahasa Arab Peserta Didik Pada Mata Kuliah Istima' i: Alashriyyah, 2(1), 12-12.

Prawiradilaga, D. S. (2016). Mozaik Teknologi Pendidikan: E-Learning. Kencana.

Priansa;, D. J. (2017). Pengembangan Strategi \& Model Pembelajaran: Inovatif, Kreatif, dan Prestatif dalam Memahami Peserta Didik (Bandung). CV Pustaka Setia. //fmipa.unj.ac.id/lib/index.php?p=show_detail\&id=101461

Putri, W. N. (2017). Pengaruh Media Pembelajaran Terhadap Motivasi Belajar Bahasa Arab Siswa Madrasah Tsanawiyah. LISANIA: Journal of Arabic Education and Literature, 1(1), 1-16. https://doi.org/10.18326/lisania.v1i1.1-16

Rosenthal, S. (2018). Motivations to seek science videos on YouTube: Free-choice learning in a connected society. International Journal of Science Education, Part B, 8(1), 22-39. https://doi.org/10.1080/21548455.2017.1371357

Rosyidi, A. W., \& Ni'mah, M. (2011). Memahami konsep dasar pembelajaran Bahasa Arab. UIN-Maliki Press. http://repository.uin-malang.ac.id/1236/

Stebleton, M. J., Soria, K. M., \& Mixon, J. D. (2011). Media Review: Facebook Me: Applying The Social Network Film to Student Development Theory and Practice. Journal of Student Affairs Research and Practice, 48(4), 505-521. https://doi.org/10.2202/1949-6605.6343

Tamim, R. M. (2013). Teachers' Use of YouTube in the United Arab Emirates: An Exploratory Study. Computers in the Schools, 30(4), 329-345. https://doi.org/10.1080/07380569.2013.844641 
Tella, A., Bode-Obanla, O., \& Age, A. S. (2020). The perspective of undergraduate students on information needs and seeking behavior through YouTube. Journal of Electronic Resources Librarianship, 32(2), 94-109. https://doi.org/10.1080/1941126X.2020.1739826

TPEN4311 - Teknologi Pendidikan Dalam Pendidikan Jarak Jauh. (2019, October 8). Perpustakaan UT. https://www.pustaka.ut.ac.id/lib/tpen4311teknologi-pendidikan-dalam-pendidikan-jarak-jauh/

Wang, H., \& Chen, C. W. (2020). Learning English from YouTubers: English L2 learners' self-regulated language learning on YouTube. Innovation in Language Learning and Teaching, 14(4), 333-346. https://doi.org/10.1080/17501229.2019.1607356

Zainuddin, \& Radliyah. (2005). Metodologi dan Strategi Alternatif Pembelajaran Bahasa Arab. Pustaka Rihlah Grup.

\section{Copyright Notice}

Authors retain copyright and grant the journal right of first publication with the work simultaneously licensed under a Creative Commons Attribution 4.0 International License that allows others to share the work with an acknowledgement of the work's authorship and initial publication in this journal. 


\section{HALAMAN INI SENGAJA DIKOSONGKAN}

